\title{
Inhibitory Effects of L-Threo-DOPS, an L-Noradrenaline Precursor, on Locus Coeruleus-Originating Neurons in the Caudate Nucleus
}

\author{
Akira HIROSE, Masashi SASA*, Yukihiro OHNO and Shuji TAKAORI \\ Department of Pharmacology. Faculty of Medicine, Kyoto University. \\ Sakyo-ku, Kyoto 606, Japan \\ Accepted August 31, 1988
}

\begin{abstract}
Electrophysiological studies using reserpine-treated cats were carried out to elucidate the effects of $L$-threo-3,4-dihydroxyphenylserine ( $L$-threo-DOPS) on the noradrenergic pathway from the locus coeruleus ( $L C$ ) to the caudate nucleus (CN) neurons, which were activated by iontophoretically applied bromocriptine, a dopamine D-2 receptor agonist. In the $\mathrm{CN}$ neurons, glutamate-induced firing was inhibited by iontophoretic application of noradrenaline, but not by repetitive stimulation of the LC or iontophoretically applied L-threo-DOPS. After intraventricular administration of L-threo-DOPS, however, LC stimulation inhibited the glutamateinduced firing. These results suggest that $\mathrm{L}$-noradrenaline that was produced from the conversion of $L$-threo-DOPS inhibited the $C N$ neurons which possess dopamine D-2 receptors.
\end{abstract}

It is well-documented that $L$-threo-3,4dihydroxyphenylserine (L-threo-DOPS) is directly converted into L-noradrenaline by $L$ aromatic amino acid decarboxylase in the brain and kidney $(1,2)$. Systemic administration of L-threo-DOPS to experimental animals, in which monoamines such as noradrenaline were depleted by reserpine or tetrabenazine, is known to increase the noradrenaline level in the brain $(3,4)$. Our previous studies have also demonstrated that noradrenaline formed from L-threo-DOPS in the locus coeruleus (LC) neurons inhibits the transmission of the spinal trigeminal nucleus neurons (5).

Narabayashi et a!. (6) reported that Lthreo-DOPS was effective in treating some symptoms of parkinsonism such as akinesia and freezing. Since degeneration of the noradrenaline-containing neurons in the LC concomitantly with degeneration of dopaminergic neurons in the substantia nigra was observed in patients with parkinsonism $(7,8)$. the effects of $L$-threo-DOPS are considered to be due to supplemental noradrenaline in the brain. Previously, we reported that about one-

\footnotetext{
* To whom correspondence should be addressed.
}

third of the caudate nucleus $(\mathrm{CN})$ neurons activated by stimulation of the pars compacta of the substantia nigra were inhibited by noradrenaline derived from the LC (9). In the $\mathrm{CN}$ neurons, the spike elicited by nigral stimulation appears to be induced by dopamine, which acts on postsynaptic dopamine D-2 receptors, since the spike was blocked by iontophoretically applied domperidone, a dopamine D-2 antagoist, and firing of the neurons was increased by iontophoretic application of D-2 agonists such as bromocriptine and quinpirole (10-13). Thus, we preformed an electrophysiological study to examine whether or not noradrenaline converted from L-threo-DOPS affects the $\mathrm{CN}$ neurons activated by a dopamine D-2 agonist.

\section{Materials and Methods}

Fourteen adult cats weighing $2.6-4.2 \mathrm{~kg}$ were given $1 \mathrm{mg} / \mathrm{kg}$, i.m., of reserpine (Daiichi Seiyaku) $24 \mathrm{hr}$ before the experiments. Surgical procedures such as cannulation into the trachea and femoral vein were carried out under ether anesthesia. The head of the animal was fixed in a stereotaxic instrument. After the operation, the ether anesthesia was replaced with $\alpha$-chloralose (30 mg/kg, i.v.), 


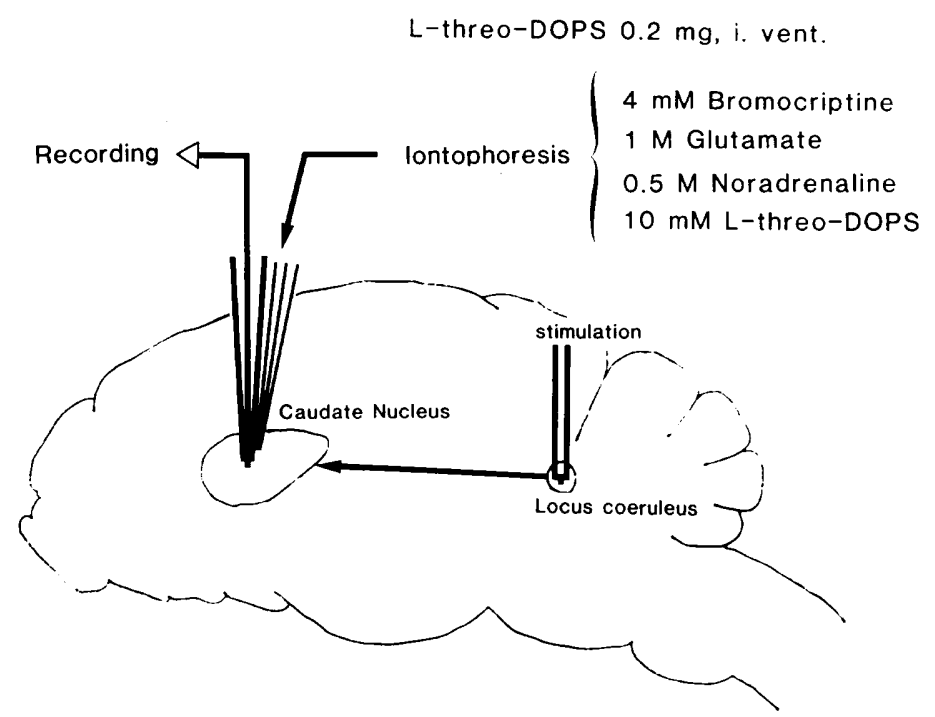

Fig. 1. Schematic representation of experimental procedures.

and the animal was immobilized with gallamine triethiodide ( $5 \mathrm{mg} / \mathrm{kg} / \mathrm{hr}$, i.v.) under artificial respiration. All wound edges and pressure points were locally anesthetized with $8 \%$ lidocaine spray throughout the experiments. Supplemental doses of $\alpha$-chloralose (each $10-15 \mathrm{mg} / \mathrm{kg}$, i.v.) were added as required. Body temperature was maintained at $36.5-37.5^{\circ} \mathrm{C}$ with a heating pad. The ECG (II lead) was continuously monitored during the experiments, and under these conditions, the animal was considered to be well-anesthetized since there were no obvious changes in the ECG when the stimulus was applied to the LC.

Single neuron activities in the head of the left CN (A: 16.0-18.0, L: 3.0-6.0, H: 3.0-8.0) (14) were recorded extracellularly using a glass-insulated silver wire microelectrode (an electrical resistance of approx. $1 \mathrm{M} \Omega$ ) attached along a seven-barreled micropipette (Fig. 1). Each pipette was filled with $4 \mathrm{mM}$ bromocriptine mesylate (Sandoz; dissolved in $0.3 \%$ tartrate, $\mathrm{pH} 4.0$ ), $1 \mathrm{M}$ monosodium L-glutamate (Sigma, pH 7.5), $0.5 \mathrm{M}( \pm)$ noradrenaline bitartrate (Sigma, $\mathrm{pH} 4.5$ ), 10 mM L-threo-DOPS (Sumitomo Seiyaku; dissolved in $1 \mathrm{~N} \mathrm{HCl}, \mathrm{pH}$ adjusted to 5.0 by adding $0.2 \mathrm{~N} \mathrm{NaOH}$ ) and $3 \mathrm{M} \mathrm{NaCl}$. These chemicals were iontophoretically applied to the immediate vicinity of the target neuron being recorded using a microiontophoresis programmer (WP-I, Model 160). A retaining current of 10-20 nA was continuously ejected to prevent the spontaneous leakage of the drugs from the pipette. L-threo-DOPS $(0.1 \mathrm{ml}$ of $0.2 \mathrm{mg})$ was applied into the right lateral ventricle (A: 14.0, L: 3.0, H: 7.5) (14) through a needle previously fixed on the skull. Spontaneous and giutamate-induced firings were continuously recorded on an ink-writing recorder (Nihon Kohden, RJG4022) through a spike counter (Dia Medical System, DSE-325P). Repetitive stimuli $(0.2$ msec, 0.1 and $0.5 \mathrm{~mA}, 20 \mathrm{~Hz}$ ) were applied to the LC (P: 2.0, L: 2.0, H: -2.0) (15) ipsilateral to the recording site for $20 \mathrm{sec}$. The data were analyzed by Student's $t$-test. After the end of the experiments, the recording and stimulating sites were marked by passing a direct current of 20-100 $\mu \mathrm{A}$ for $10-20 \mathrm{sec}$ and then checked by staining with cresyl violet. Further details of the experimental procedures have been described elsewhere (16).

\section{Results}

Most $\mathrm{CN}$ neurons had a low spontaneous firing rate of less than $1 / \mathrm{sec}$. Iontophretic application of bromocriptine at doses of 100$200 \mathrm{nA}$ increased the firing rate in 22 of 45 $\mathrm{CN}$ neurons in 14 reserpine-treated cats (Fig. 2 ), as reported previously in the untreated 

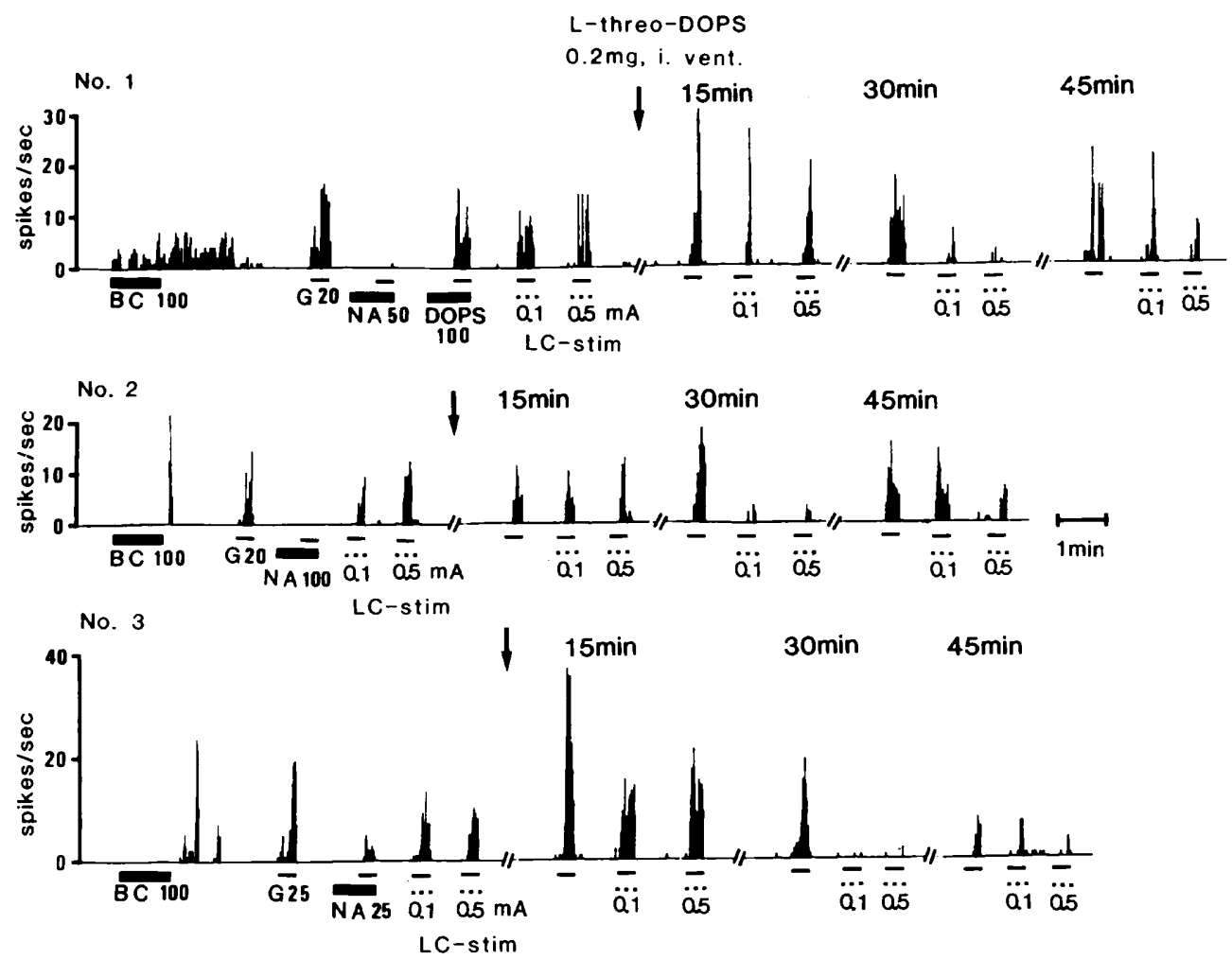

Fig. 2. Increases in the firing rate induced by iontophoretic application of bromocriptine (BC) and glutamate $(G)$, and effects of iontophoretically applied noradrenaline (NA) and L-threo-DOPS (DOPS) as well as repetitive stimulation of the locus coeruleus (LC-stim: 0.1 and $0.5 \mathrm{~mA}, 20 \mathrm{sec}$ ) on the Ginduced firing of 3 caudate nucleus neurons in the reserpine-treated cats before and after intraventricular (i. vent.) administration $(\downarrow)$ of L-threo-DOPS $(0.2 \mathrm{mg})$. Periods during iontophoretic application of drugs and LC-stim are indicated by horizontal bars and dotted liries, respectively. Numbers under the bars and dotted lines show the applied current in $\mathrm{nA}$ and stimulus intensity in $\mathrm{mA}$ to the LC, respectively.

cats (12). The increase in firing rate was seen 10-60 sec after the onset of the application, and it lasted for 10-120 sec after the cessation of the application.

In the $22 \mathrm{CN}$ neurons activated by bromocriptine, the effects of iontophoretically applied noradrenaline and L-threo-DOPS on glutamate-induced firing were examined. Iontophoretic application of glutamate (20$25 \mathrm{nA}$ ) elicited a reproducible firing in all neurons tested with firing rates ranging from 10 to $30 / \mathrm{sec}$. When noradrenaline $(25-100$ $\mathrm{nA}$ ) was applied for $60 \mathrm{sec}$, a decrease in the glutamate-induced firing was observed in 12 of the 22 neurons. In contrast, iontophoretically applied L-threo-DOPS up to $200 \mathrm{nA}$ did not affect the glutamate-induced firing in any neuron. The glutamate-induced firing was not altered by repetitive stimulation of the LC (Fig. 2).

In the next series of experiments, the effects of LC stimulation after intraventricular administration of L-threo-DOPS $(0.2 \mathrm{mg})$ were examined in $7 \mathrm{CN}$ neurons activated by iontophoretically applied bromocriptine and inhibited by noradrenaline. When repetitive stimuli ( 0.1 and $0.5 \mathrm{~mA}$ ) were applied to the LC for $20 \mathrm{sec}$, none of the 7 neurons exhibited over $50 \%$ inhibition of the maximum firing induced by glutamate before intraventricular administration of L-threo-DOPS (Table 1). After subsequent administration of $\mathrm{L}$-threo-DOPS into the lateral ventricle, however, the glutamate-induced firing was suppressed by LC stimulation in all neurons tested. A slight inhibition was seen $15 \mathrm{~min}$ 
Table 1. Effects of iontophoretically applied noradrenaline (NA) and L-threo-DOPS and locus coeruleus stimulation (LC-stim) on glutamate-induced firing of the caudate nucleus neurons in reserpinetreated cats

\begin{tabular}{|c|c|c|c|c|c|c|c|}
\hline \multirow{2}{*}{$\underset{(m A)}{\text { LC-stim }}$} & \multirow{2}{*}{$\begin{array}{l}\text { Neuron } \\
\text { number }\end{array}$} & \multirow{2}{*}{$\begin{array}{l}\text { NA (25-- } \\
100 \text { nA) }\end{array}$} & \multirow{2}{*}{$\begin{array}{c}\text { L-threo- } \\
\text { DOPS } \\
(100-200 \\
n A)\end{array}$} & \multicolumn{4}{|c|}{$\begin{array}{l}\text { LC-stim before and after intraventricular } \\
\text { administration }(0.2 \mathrm{mg}) \text { of L-threo-DOPS }\end{array}$} \\
\hline & & & & Before & $15 \mathrm{~min}$ & $30 \mathrm{~min}$ & $45 \mathrm{~min}$ \\
\hline \multirow[t]{8}{*}{0.1} & 1 & 6 & 100 & 71 & 87 & 39 & 96 \\
\hline & 2 & 0 & $-a$ & 67 & 92 & 21 & 94 \\
\hline & 3 & 17 & - & 68 & 38 & 5 & 88 \\
\hline & 4 & 24 & 91 & 107 & 2 & 59 & 65 \\
\hline & 5 & 4 & - & 114 & 93 & 32 & 7 \\
\hline & 6 & 50 & 85 & 75 & - & 92 & 17 \\
\hline & Mean & 16.8 & 92.0 & 83.7 & 62.4 & $41.3^{*}$ & 61.2 \\
\hline & S.E. & 7.6 & 4.4 & 8.6 & 18.3 & 12.5 & 16.2 \\
\hline \multirow[t]{8}{*}{0.5} & 1 & & & 88 & 68 & 17 & 35 \\
\hline & 2 & & & 87 & 108 & 21 & 50 \\
\hline & 3 & & & 58 & 57 & 11 & 50 \\
\hline & 4 & & & 93 & 5 & 53 & 27 \\
\hline & 6 & & & 64 & 89 & 100 & 8 \\
\hline & 7 & 31 & - & 85 & 25 & - & 36 \\
\hline & Mean & & & 79.2 & 58.7 & $40.4^{*}$ & $34.3^{* *}$ \\
\hline & S.E. & & & 5.9 & 15.8 & 16.6 & 6.4 \\
\hline
\end{tabular}

a: not tested. Data show percentage of maximum firing rate with the treatment against that without the treatment. ${ }^{*} P<0.05,{ }^{* *} P<0.01$, significantly different from the value before intraventricular administration of L-threo-DOPS.

after the administration of L-threo-DOPS, and a significant reduction of the firing rate was observed $30-45 \mathrm{~min}$ after application of L-threo-DOPS when the stimuli were applied to the LC (Fig. 2 and Table 1 ).

\section{Discussion}

About $50 \%$ of the examined $\mathrm{CN}$ neurons were activated by bromocriptine, and these neurons were considered to receive excitatory input from the substantia nigra via dopamine D-2 receptors, as already reported (11-13). Furthermore, half of the neurons activated by bromocriptine were inhibited by iontophoretic application of noradrenaline in reserpine-treated animals. These results are in line with the previous findings (9) that spike generation of the $\mathrm{CN}$ neurons upon nigral stimulation was inhibited by iontophoretically applied noradrenaline as well as by stimuli applied to the LC preceding the test stimulation to the substantia nigra. Therefore, these neurons presumably possess both dopamine D-2 and adrenergic receptors. When the effects of LC stimulation on these $\mathrm{CN}$ neurons were examined in reserpinetreated animals, no inhibition of the glutamate-induced firing was observed. The lack of effects of LC stimulation was probably due to the depletion of noradrenaline from the noradrenergic nerve terminals, since $1 \mathrm{mg} / \mathrm{kg}$ (i.m.) of reserpine was sufficient to markedly reduce the amine (17).

However, the inhibition by the LC stimulation was seen in all neurons tested after intraventricular administration of $\mathrm{L}$-threoDOPS. Systemic administration of L-threoDOPS to the animals treated with reserpine reportedly increased the noradrenaline content in the brain (4). In addition, $\beta$-adrenergic receptor-mediated inhibition of the spinal trigeminal nucleus neurons by LC condi- 
tioning stimulation was observed following intraventricular application of L-threo-DOPS to the reserpine-treated animals in a previous study (5), which was performed under experimental conditions similar to those in the present study. Therefore, the inhibition induced by LC stimulation described here is considered to be due to noradrenaline converted from $L$-threo-DOPS in the noradrenergic neurons derived from the $L C$. The possibility that L-threo-DOPS itself acted on the $\mathrm{CN}$ neurons can be excluded, since the amino acid iontophoretically applied to the target neuron had no effects in both the present and previous studies (5).

Although the uptake of noradrenaline into the synaptic vesicles is inhibited in the animals treated with reserpine, some noradrenaline formed from L-threo-DOPS in the cytoplasm is still taken up into the vesicles since the degree of inhibition of the uptake is dependent upon the doses of reserpine, as described previously $(5,18)$. In conclusion, it is suggested that L-threo-DOPS acts on some of the $\mathrm{CN}$ neurons after conversion to noradrenaline in the noradrenergic neurons originating in the $\mathrm{LC}$.

Acknowledgments: The authors are grateful to Sumitomo Seiyaku Company (Osaka, Japan) and Sandoz (Basel, Switzerland) for the gifts of L-threoDOPS and bromocriptine, respectively.

\section{References}

1 Puig, M., Bartholini, G. and Pletscher, A.: Formation of noradrenaline in the rat brain from the four stereoisomers of 3,4-dihydroxyphenylserine. Naunyn Schmiedebergs Arch. Pharmacol. 281, 443-446 (1974)

2 Inagaki, C. and Tanaka, C.: Characteristics of enzymic decarboxylation of L-threo-3,4-dihydroxyphenylserine using hog renal $L$-aromatic amino acid decarboxylase. Biochem. Pharmacol. 27, 1081-1086 (1978)

3 Kato, T., Katsuyama, M., Karai, N., Hirose, A., Nakamura, M. and Katsube, J.: Reversal of the reserpine-induced ptosis by L-threo-3,4-dihydroxyphenylserine (L-threo-DOPS), a (-)norepinephrine precursor, and its potentiation by imipramine or nialamide. Naunyn Schmiedebergs Arch. Pharmacol. 332, 243-246 (1986)

4 Katsuyama, M., Kato, T., Karai, N., Nakamura, M. and Katsube, J.: Reversal by L-threo-3,4-dihydroxyphenylserine (L-threo-DOPS), a L- norepinephrine precursor of reserpine- or tetrabenazine-induced hypothermia. Arch. Int. Pharmacodyn. Ther. 283, 61-70 (1986)

5 Sasa, M., Ohno, Y., Nabatame, H., Yoshimura, N. and Takaori, S.: Effects of L-threo-DOPS, a $L$-noradrenaline precursor, on locus coeruleusoriginating neurons in spinal trigeminal nucleus. Brain Res. 420, 157-161 (1987)

6 Narabayashi, H., Kondo, T., Hayashi, A., Suzuki, T. and Nagatsu, T.: L-threo-3,4-dihydroxyphenylserine treatment for akinesia and freezing of parkinsonism. Proc. Japan. Acad. 57, Ser. B 351-354 (1981)

7 Greenfield, J.G. and Bosanquet, F.D.: The brainstem lesions in parkinsonism. J. Neurol. Neurosurg. Psychiatry 16, 213-226 (1953)

8 Hornykiewicz, 0.: Dopamine and its physiological significance in the brain functions. In The Structure and Functions of Nervous Tissue, Edited by Bourne, G.H., Vol. VI, p. 367-415, Academic Press, New York (1972)

9 Fujimoto, S., Sasa, M. and Takaori, S.: Inhibition from locus coeruleus of caudate neurons activated by nigral stimulation. Brain Res. Bull. 6, 267-274 (1981)

10 Creese, I., Sibley, D.R., Hamblin, M.W. and Leff, S.E.: The classification of dopamine receptors: Relationship to radioligand binding. Annu. Rev. Neurosci. 6, 43-71 (1983)

11 Ohno, Y., Sasa, M. and Takaori, S.: Dopamine D-2 receptor-mediated excitation of caudate nucleus neurons from the substantia nigra. Life Sci. 37, 1515-1521 (1985)

12 Ohno, Y., Sasa, M. and Takaori, S.: Excitation by dopamine D-2 receptor agonists, bromocriptine and LY 171555, in caudate nucleus neurons activated by nigral stimulation. Life Sci. 38, 1867-1873 (1986)

13 Ohno, Y., Sasa, M. and Takaori, S.: Coexistence of inhibitory dopamine D-1 and excitatory D-2 receptors on the same caudate nucleus neurons. Life Sci. 40, 1937-1945 (1987)

14 Snider, R.S. and Niemer, W.T.: A Stereotaxic Atlas of the Cat Brain. University of Chicago Press, Chicago (1961)

15 Berman, A.L.: The Brain Stem of the Cat: A Cytoarchitectonic Atlas with Stereotaxic Coordinates. University of Wisconsin Press. Madison (1968)

16 Sasa, M., Ohno, Y., Ito, J., Kashii, S., Utsumi, S. and Takaori, S.: Beta-receptor involvement in locus coeruleus-induced inhibition of spinal trigeminal nucleus neurons: Microiontophoretic and HRP studies. Brain Res. 377, 337-343 (1986) 
17 Sasa, M., Munekiyo, K., Ikeda, H. and Takaori, S.: Noradrenaline-mediated inhibition by locus coeruleus of spinal trigeminal neurons. Brain Res. 80, 443-460 (1974)

18 Seidler, F.J., Kirksey, D.F., Lau, C., Whitmore,
W.L. and Slotkin, T.A.: Uptake of $(-)-{ }^{3} \mathrm{H}-$ norepinephrine by storage vesicles prepared from whole rat brain: Properties of the uptake system and its inhibition by drugs. Life Sci. 21, 1075-1086 (1977) 